\title{
Composición Química Proximal, Capacidad Antioxidante y Actividad Antifúngica de Peciolo de Nalca (Gunnera tinctoria)
}

\author{
Pedro Zamorano ${ }^{(1)^{*}}$, Marcela Morales ${ }^{(2)}$, Benjamín A. Rojano ${ }^{(2)}$ \\ (1) Escuela de graduados, Facultad de Ciências Agrarias, Universidade Austral de Chile, Avenida Carlos \\ Imanes Del Campo, Campus Islã Teja S/N, Maldívia, Chile (e-mail: pedro.zamorano.a@gmail.com). \\ (2) Laboratorio Ciencia de los Alimentos, Facultad de Ciencias, Universidad Nacional de Colombia, \\ Calle 59 A №63-20, Bloque 19A, Medellín, Colombia. (e-mail: dimmoralessav@unal.edu.co; \\ brojano@unal.edu.co).
}

* Autor a quien debe ser dirigida la correspondencia

Recibido Ago. 18, 2017; Aceptado Oct. 10, 2017; Versión final Nov. 27, 2017, Publicado Abr. 2018

\begin{abstract}
Resumen
El presente estudio investigó el contenido de antocianinas y polifenoles totales de Nalca. La Nalca (Gunnera tinctoria) es una planta de reconocida importancia en el sur de Chile, ya que posee un peciolo comestible el cual provee de ingresos a agrupaciones rurales que se dedican a su comercialización. Sin embargo, no existen antecedentes relacionados a sus metabolitos secundarios. La capacidad antioxidante fue determinada a través del método DPPH, y su actividad biológica fue evaluada sobre Cladophialophora y Cryptococcus laurentii. Los resultados indicaron que el peciolo de nalca posee un elevado contenido de fibra cruda (11.57\%). Así mismo, presentó una alta concentración de polifenoles totales $(7291.1 \pm 224 \mathrm{mg}$ GAE/100 g base seca) y una elevada capacidad antioxidante $(105735 \pm 3008.14 \mu$ moles TEAC/100 $\mathrm{g}$ base seca). Por otro lado, presentó un efecto fungicida sobre los microorganismos ensayados. Los resultados obtenidos sugieren que la Nalca es una promisoria fuente de compuestos bioactivos y una potencial alternativa fungicida.
\end{abstract}

\section{Proximate Chemical Composition, Antioxidant Capacity and Antifungal Activity of Nalca (Gunnera tinctoria)}

\begin{abstract}
The present study investigated the anthocyanins and total polyphenols contents. Nalca (Gunnera tinctoria) is a plant of recognized importance in southern Chile, since it has an edible petiole which provides incomes to rural groups that are engaged in their commercialization. Nevertheless, no background exists about his secondary metabolites. The antioxidant capacity was determined by DPPH method, and its biological activity was evaluated against Cladophialophora and Cryptococcus laurentii. The results indicated that the Nalca petiole has high crude fiber content $(11.57 \%)$. Also, it presented a high concentration of total polyphenols $(7291.1 \pm 224 \mathrm{mg} \mathrm{GAE} / 100 \mathrm{~g}$ dry weight) and a high antioxidant capacity ((105735 \pm 3008.14 $\mu$ moles TEAC/100 g dry weight). On the other hand, the extract showed a fungicide effect against the microorganisms assayed. The results suggest that Nalca is promissory source of bioactive compounds and a potential fungicide alternative in development.
\end{abstract}

Keywords: antioxidant capacity; total polyphenols; antifungal activity; Gunnera tinctoria; Nalca 


\section{INTRODUCCIÓN}

En la actualidad se observa una creciente preocupación y conocimiento acerca de la importancia de los hábitos alimenticios, por lo que todos los esfuerzos están dirigidos a la investigación e implementación de dietas más equilibradas (MINSAL, 2014). Esta situación se origina a raíz de los cuestionamientos que han recibido dichos hábitos, los cuales están relacionados al estilo y calidad de vida de la población moderna, la que a diario tiene fácil acceso a alimentos de baja calidad nutricional, predominando la comida rápida (que presenta un elevado contenido de grasas saturadas) y bebidas o alimentos que contienen altos niveles de azúcar (Wilson et al., 2017). En Chile, a medida que el desarrollo del país ha ido en aumento, también lo han hecho sus índices de estrés, sedentarismo, obesidad, enfermedades cardiovasculares y enfermedades asociadas, por lo que se han diseñado estrategias y medidas para revertir dicha situación a través de programas tales como "elige vivir sano" y "el plato de tu vida"; iniciativas que pretenden mejorar la calidad de vida de las personas a través de uno de sus pilares fundamentales: la alimentación (MINSAL, 2014). Es por esta razón que el concepto de "nutrición adecuada" (dieta que aporta los nutrientes necesarios para el buen funcionamiento del organismo), está siendo sustituido por "nutrición óptima", ya que la evidencia científica sugiere que algunos alimentos mejoran nuestra salud y contribuyen a prevenir determinadas enfermedades (Cadaval et al., 2005).

Enfermedades tales como diabetes tipo II, desórdenes inmunes, trastornos neurodegenerativos, varios tipos de cáncer y enfermedades cardiovasculares pueden generarse producto del estrés oxidativo al cual nuestro organismo está expuesto de manera constante; por lo que un alto consumo de frutas y verduras (y por ende, una mayor ingesta de compuestos bioactivos), reduciría o prevendría la incidencia de dichos padecimientos (Jeszka-Skowron et al., 2017; Mazo et al., 2016). Dentro de los metabolitos secundarios se encuentran polifenoles, carotenos, vitaminas hidrosolubles y liposolubles, los cuales pueden actuar como antioxidantes y también como antimicrobianos (Prior, et al., 2003). Estos se pueden encontrar de manera natural en nuestra dieta, y presentan una estructura química ideal para inhibir o disminuir los efectos nocivos de radicales libres sobre la fisiología normal del organismo (Ramirez et al., 2015).

Por todo lo anteriormente expuesto, es necesario conocer la composición de compuestos bioactivos en nuestras frutas, verduras y especies de origen vegetal; con el propósito de potenciar su presencia en nuestra dieta (Vega et al., 2017). Dentro de estas se encuentra Gunnera tinctoria (Molina) Mirb. (= Gunnera chilensis Lam.), producto forestal no maderable (PFNM) conocido comúnmente como Nalca, Ruibarbo chileno o Pangue (Zamorano et al., 2017). Nalca pertenece a la familia monogenérica Gunneracea, y de acuerdo a Petzold et al., (2006) es de reconocida importancia en el sur de Chile principalmente a nivel de la pequeña agricultura en la que predomina la explotación de subsistencia; ya que es una de las pocas plantas ornamentales que posee un peciolo comestible, el cual a través de su comercialización provee recursos y mayores ingresos a las personas y/o agrupaciones rurales que se dedican a su recolección y venta informal. En Sudamérica, esta especie se encuentra distribuida desde Chile y Argentina, hasta Colombia y Venezuela; también se ha reportado en Perú, Ecuador y Bolivia (Petzold et al., 2006).

A raíz de la escaza divulgación científica que existe sobre Nalca, esta investigación tiene el objetivo de realizar un aporte al conocimiento científico y a la revalorización de una planta endémica de Chile; a través de la determinación de su composición nutricional y antioxidante. Además de evaluar su efecto antagonista sobre Cryptococcus laurentii y Cladophialophora.

\section{MATERIALES Y MÉTODOS}

En la presente sección se describen los reactivos y equipos utilizados; la recolección, preparación y extracción de la muestra. Además de las metodologías utilizadas en la determinación de los compuestos bioactivos, capacidad antioxidante y actividad antifúngica de peciolo de nalca.

\section{Reactivos y equipos}

Diphenyl-1-2,2 picrylhydrazyl (DPPH); 6-hydroxy-2,5,7,8-tetramethyl chromane-2-carboxyli acid (Trolox); 3,4,5-trihydroxybenzoic acid (ácido gálico) fueron obtenidos de Sigma-Aldrich ${ }^{\circledR}$ (St. Louis,MO, USA). Reactivo de Folin Ciocalteu y carbonato de sodio fueron adquiridos de Merck (Alemania). Metanol y otros solventes fueron obtenidos de Fisher Scientific Co. (Fair Lawn, NJ, USA). El agua utilizada en los experimentos fue grado HPLC. Los ensayos de absorción UV-vis fueron realizados en un lector de placas Thermo Scientific Multiskan ${ }^{\circledast}$ Spectrum UV-vis.

\section{Material Vegetal}

El material vegetal fue recolectado en la comuna de Los Lagos -Región de Los Ríos, Chile - (31 m.s.n.m y $12,3^{\circ} \mathrm{C}$ de temperatura promedio). Luego de ser almacenado en bolsas de polipropileno perforadas fue liofilizado y llevado al laboratorio para los análisis respectivos. 


\section{Preparación y extracción de la muestra}

Para la determinación de metabolitos secundarios, capacidad antioxidante y actividad biológica; $2.5 \mathrm{~g}$ de muestra liofilizada fue disuelta y homogenizada con $25 \mathrm{ml}$ de $\mathrm{MeOH}$-Ac. Fórmico (99:1), y posteriormente extraída por $1 \mathrm{~h}$. Este procedimiento se realizó tres veces. La sumatoria de los 3 sobrenadantes fue concentrada en un rotavapor a $60^{\circ} \mathrm{C}$ obteniéndose $0.37 \mathrm{~g}$ del extracto de peciolo de Nalca. El pellet final fue resuspendido en $25 \mathrm{ml}$ de agua desionizada. Este último extracto fue almacenado a $4^{\circ} \mathrm{C}$ hasta realizar los experimentos.

\section{Análisis proximal}

Cenizas totales (AOAC, 1996; método 942.05), humedad (AOAC, 1996; método 930.15), proteína cruda (AOAC, 1996: método 990.03), extracto etéreo (AOAC, 1996; método 832p) y fibra cruda (AOAC, 1996; método 978.10) fueron determinados. Carbohidratos fueron determinados por diferencia. Cada muestra fue analizada en triplicado, y todos los valores proximales fueron reportados en porcentaje.

\section{Fenoles totales}

La determinación de fenoles se realizó por el método colorimétrico de Folin-Ciocalteu diseñado por Singleton et al., (1965). $50 \mu \mathrm{L}$ de muestra fueron adicionados a $125 \mu \mathrm{L}$ del reactivo de Folin, y $400 \mu \mathrm{L}$ de carbonato de Sodio $7.1 \%(\mathrm{p} / \mathrm{v})$, ajustando con agua destilada hasta $1000 \mu \mathrm{L}$. La lectura espectrofotométrica se realizó a $760 \mathrm{~nm}$ y se comparó con la curva patrón usando como estándar ácido gálico. Los resultados fueron expresados como mg de ácido gálico equivalente: GAE/100 g muestra seca.

\section{Antocianinas}

La concentración de antocianinas totales fue determinada mediante el método diferencial de $\mathrm{pH}$. Las absorbancias se midieron a 530 y $700 \mathrm{~nm}$ en buffers de $\mathrm{pH} 1,0$ y 4,5; usando la expresión $A=\left[\left(A_{530}-A_{700}\right)\right.$ pH1.0 - $\left(A_{530}-A_{700}\right)$ pH4.5], con un coeficiente de extinción molar para el cianidin-3-glucósido de 26900. Los resultados fueron expresados como mg equivalentes de cianidina-3-glucósido/L (Gaviria et al., 2009).

\section{Evaluación por el método DPPH}

La actividad captadora de radicales sobre el radical DPPH fue cuantificada usando el método propuesto por Brand-Williams et al. (1995), con algunas modificaciones. El método se basa en la reacción de $10 \mathrm{~mL}$ de muestra con $990 \mathrm{~mL}$ de solución DPPH durante 30 minutos a temperatura ambiente. La disminución de la absorbancia, asociada con la reducción en la concentración de DPPH fue medida a $517 \mathrm{~nm}$. Los resultados fueron expresados en $\mu \mathrm{mol}$ Trolox equivalentes por $100 \mathrm{~g}$ de muestra seca.

\section{Cepas fúngicas}

Para la determinación de la actividad antimicrobiana se utilizaron cepas de Cryptococcus laurentii y Cladophialophora. Los microorganismos utilizados fueron aislados de una sala de maduración de quesos, perteneciente a pequeños productores de la región de Los Ríos. El muestreo, cultivo, aislamiento e identificación fueron realizados en el Instituto de Microbiología Clínica de la Universidad Austral de Chile.

\section{Preparación de la suspensión}

A partir de cada cepa se preparó una suspensión, que consistió en un inóculo de cada microorganismo resuspendido en suero fisiológico estéril. Posteriormente, esta suspensión fue homogenizada a través de agitación manual hasta alcanzar un estándar de turbidez igual a la presentada en un tubo patrón de densidad óptica 0,5 Mc Farland (longitud de onda de $530 \mathrm{~nm}$ ). La concentración de los inóculos para Cryptococcus laurentii y Cladophialophora correspondieron a $1-5 \times 10^{6} \mathrm{UFC} / \mathrm{ml}$ y $0.4-3.1 \times 10^{6} \mathrm{UFC} / \mathrm{ml}$ respectivamente (Cantón et al., 2007).

\section{Test de susceptibilidad}

La susceptibilidad de los microorganismos aislados se determinó mediante el método de difusión de disco Kirby-Bauer en placas de agar Muller Hinton (Bauer et al., 1996), con algunas modificaciones. Todos los medios utilizados en la presente investigación se obtuvieron de Oxoid, Hampshire, Reino Unido.

Método de difusión de pozos en agar 
La actividad antifúngica del peciolo de Nalca se determinó mediante el método de difusión de pozos en agar (Bauer et al., 1996). Para aplicar esta técnica, se hicieron 6 pocillos en el agar (6 mm de diámetro). Posteriormente, la placa fue inoculada, donde la suspensión de hongos (Cryptococcus laurentii: 1-5 x10 6 UFC/ml y Cladophialophora: 0.4-3.1 ×106 UFC/ml) fue absorbida con una tórula de algodón estéril. Luego, se sembró por el método de estría sobre el agar en tres direcciones diferentes en un ángulo de $90^{\circ}$. Paralelamente, se prepararon 5 diluciones a partir del extracto puro, de las cuales se depositó en cada pocillo $25 \mu \mathrm{l}$ de extracto. El pocillo final contenía $25 \mu \mathrm{l}$ de solvente (70\% de alcohol), lo que correspondía al control negativo. Finalmente, las placas se incubaron a $25^{\circ} \mathrm{C}$ y $32^{\circ} \mathrm{C}$ (moho y levadura respectivamente) durante 20 días. Los experimentos se realizaron por triplicado.

\section{Determinación de la actividad antifúngica}

La actividad antifúngica se evaluó observando y determinando la presencia y/o ausencia de halos de inhibición formados alrededor del pocillo que contenía el extracto puro y las respectivas diluciones. La determinación del efecto fungistático y/o fungicida se realizó visualmente considerando el tiempo de inhibición del crecimiento en agar Mueller Hinton. Estas mediciones se realizaron después de siete y 20 días.

\section{RESULTADOS Y DISCUSIÓN}

Los resultados se presentan y discuten en forma separada en las siguientes subsecciones: composición química proximal, metabolitos secundarios, capacidad antioxidante, tratamiento de muestra y actividad antifúngica. Cabe mencionar que los resultados de 1) caracterización química, 2) polifenoles totales y 3) capacidad antioxidante son presentados como la media \pm la desviación estándar y expresados en términos de base seca (BS).

\section{Caracterización químico proximal}

En la tabla 1 se muestra la composición química proximal de peciolo de Nalca. Destaca el porcentaje determinado para proteína $(7.59 \% \pm 0.27)$; el cual es similar al reportado para limón y naranja $(7.04 \%$ y $6.40 \%$ respectivamente) (Ibrahim et al., 2011). Por otra parte, el valor obtenido para fibra cruda $(11.57 \pm 0.1)$ es ampliamente superior al determinado en otras frutas de consumo masivo, tales como ciruela (3.0\%), naranja (3.30\%), papaya (5.31\%) y kiwi (5.71\%) (Morillas-Ruiz y Delgado, 2012). El término fibra cruda en nutrición humana se refiere a los componentes de los alimentos que no son digeribles por los sistemas enzimáticos de los mamíferos (Slavin, 2003); por lo que este hallazgo sugiere que el peciolo de nalca posee un alto valor dietético.

Tabla 1: Composición química proximal de peciolo de Nalca.

\begin{tabular}{lr}
\hline Variables composición proximal & $(\%)$ \\
\hline Humedad & $83.51 \pm 0.18$ \\
Cenizas totales & $7.75 \pm 0.10$ \\
Proteínas & $7.59 \pm 0.27$ \\
Extracto etéreo & $0.80 \pm 0.1$ \\
Fibra cruda & $11.57 \pm 0.2$ \\
Carbohidratos & 72.29 \\
\hline
\end{tabular}

\section{Metabolitos secundarios}

Los polifenoles constituyen un grupo de metabolitos secundarios encontrados en especies vegetales; que presentan a través de su capacidad antioxidante y actividad biológica una serie de efectos favorables sobre la salud humana (Prior et al., 2003). En el presente estudio la concentración determinada para polifenoles y antocianinas fue de $7291.1 \pm 224 \mathrm{mg} \mathrm{GAE} / 100 \mathrm{~g}$ BS y $4.1 \pm 0.06 \mathrm{mg}$ equivalentes de cianidina-3-glucósido/L respectivamente (Tabla 2). El contenido de polifenoles totales es similar al reportado para calafate (Berberis microphylla) (6553 mg GAE/100 g BS) (Ramirez et al., 2015); y superior al determinado para maqui (Aristotela chilensis) (4900 mg GAE/100 g BS) (Genskowsky et al., 2016) y arándano (Vaccinium corymbosum) (4586 $\mathrm{mg} \mathrm{GAE} / 100 \mathrm{~g} \mathrm{BS}$ ) (Ramirez et al., 2015). Es posible atribuir el alto contenido de polifenoles totales a las condiciones ambientales, ya que diversos estudios han demostrado que la síntesis de polifenoles es favorecida por las condiciones de estrés a las cuales las especies vegetales se ven expuestas en climas adversos o de estrés (Iglesias et al., 1999). De acuerdo a esto, Lu et al., (2009) sugirieron que la exposición lumínica y las temperaturas son responsables del $52 \%$ de la variación del contenido de compuestos polifenólicos en diferentes plantas; condiciones que son aplicables a nuestra investigación, puesto que el material vegetal fue cosechado durante un mes (Octubre) que presentó temperaturas más altas en comparación a los promedios históricos (Asuntos públicos, 2016). 
Por otro lado, la baja concentración de antocianinas indica que no son un grupo principal dentro de los polifenoles cuantificados, lo cual se observa a simple vista en el color del peciolo, ya que la principal característica de estos metabolitos es la de otorgar colores (rojo, violeta y azul) a las frutas y especies vegetales en las que se encuentran (Tatsuzawa et al., 2010). Cabe destacar que otros factores como sequía, aumento en las temperaturas principalmente nocturnas, procesamiento, desarrollo e incluso leves diferencias genéticas entre organismos de la misma especie influyen directamente en los niveles de antocianinas. Además, el exceso de radiación ultra violeta afecta los genes que codifican la síntesis de flavonoides (chalcona sintasa (CHS) y fenilalanina amonia liasa (PAL)), y por ende la formación de antocianinas (Iglesias et al., 1999).

\section{Capacidad antioxidante}

La capacidad antioxidante cuantificada para peciolo de nalca fue de $105735 \pm 3008.14 \mu$ moles TEAC/100 g BS (Tabla 2). Estos valores son superiores a los reportados para arándano azul (Vaccinium myrtillus L.) (20000 - $40000 \mu$ moles TEAC/100 g BS) (Bujor et al., 2016); bayas de goji (Lycium barbarum) (16221 $\mu$ moles TEAC/100 g BS); y para arándano rojo (Vaccinium macrocarpon and oxycoccus) (3955 $\mu$ moles TEAC/100 g BS) (Jeszka-Skowron et al., 2017). Diversos estudios han reportado una alta correlación entre la actividad antioxidante y sus contenidos polifenólicos (Ruiz et al., 2010); aunque cabe mencionar que cada especie vegetal tiene su propio comportamiento en la síntesis de compuestos bioactivos, ya que incluso especies vegetales genéticamente idénticas que crezcan en lugares y condiciones distintas presentan notables diferencias (Iglesias et al., 1999).

Tabla 2: Compuestos bioactivos y capacidad antioxidante en peciolo de nalca.

\begin{tabular}{lr}
\hline Compuestos/Metodología & Peciolo de Nalca \\
\hline Fenoles totales (mg GAE) & $7291.1 \pm 224$ \\
Antocianinas totales (mg Eq Cianidina-3- & $4.1 \pm 0.06$ \\
glucósido/L) & $105735 \pm 3008.14$ \\
DPPH (umol Trolox Eq)
\end{tabular}

Los flavonoides constituyen el grupo de compuestos fenólicos en plantas más abundante y diverso, con aproximadamente 4000 compuestos. Según Singleton y Rossi (1965), los grupos OH en las posiciones 3'-, 4'-, 5'- del anillo B de los flavonoides incrementan la actividad antioxidante del compuesto (a diferencia de los compuestos fenólicos con un solo grupo hidroxilo). Y, desde el punto de vista de los radicales libres, estos causan diferente reactividad con los compuestos fenólicos en función de su estructura. De acuerdo a esto el radical DPPH posee una alta selectividad, ya que no reacciona con flavonoides que carezcan de grupos $\mathrm{OH}$ en un anillo $\mathrm{B}$, así como tampoco lo hace con ácidos aromáticos que contengan solo un grupo OH. Por lo tanto, la alta capacidad antioxidante medida a través de la técnica DPPH, propone una elevada eficiencia por parte de los polifenoles presentes en nalca, además de sugerir que son altamente lipofílicos (Prior et al., 2003).

\section{Tratamiento de la muestra}

Las altas concentraciones de polifenoles totales y actividad antioxidante cuantificadas se asocian además de la especie, a la preparación de la muestra y metodología de extracción utilizada en este estudio. Nuestros resultados sugieren una influencia positiva del solvente empleado (metanol); coincidiendo con lo expuesto por (Rostagno et al., 2003), quienes observaron que utilizando agua como disolvente el rendimiento de extracción es considerablemente inferior al obtenido con metanol, producto de que el agua es un solvente que aumenta el volumen del material vegetal, incrementando de esta forma la superficie de contacto y solubilidad del material orgánico con menor polaridad (exponiéndolo notablemente), pero que a su vez es incapaz de arrastrar. Por otra parte, Sulaiman et al., (2011) luego de estudiar el efecto de los solventes en la extracción de polifenoles de 37 especies vegetales, informó que el agua destilada fue el solvente más ineficiente para extraer compuestos polifenólicos; infiriendo que dicha situación se debió a la oxidación de los fenoles totales producto del accionar de la polifenol oxidasa, la cual se encuentra activa en medio acuoso; mientras que en los extractos de metanol y etanol permanece inactiva.

Oyvind y Kenneth (2006) reportaron que metabolitos tales como catequinas, proantocianidinas, ácidos fenólicos, flavonoles, procianidinas, ácido elágico y flavonas son compuestos bioactivos que presentan una mayor solubilidad en solventes metanólicos; asociando dicha propiedad a la cantidad de grupos hidroxilos insustituidos o azúcares presentes en su estructura; la que además está relacionada a una mayor capacidad antioxidante frente a radicales libres. 
Por otra parte, el tratamiento previo de liofilización potenció los resultados obtenidos, ya que en esta técnica las bajas temperaturas empleadas eliminan el shock térmico, y por ende se disminuye el colapso estructural al cual se exponen los compuestos termosensibles (Ratti, 2001). De esta manera se mantienen significativamente las propiedades físicoquímicas relacionadas con la muestra a través de la eliminación de agua; deteniendo reacciones de deterioro, protegiendo la estructura primaria de esta, y con ello concentrando y reteniendo gran cantidad de sus componentes. Así también, apoya la inactivación enzimática que genera oxidación en los sustratos, favoreciendo la estabilidad y actividad de los metabolitos secundarios (Georgé et al., 2011).

Además, de acuerdo con la literatura la utilización de solventes acidificados incrementa los rendimientos de extracción de los compuestos polifenólicos tales como antocianidinas, proantocianidinas, y para la extracción de los flavonoides en general (Ju y Howard, 2003). Particularmente, Dorta et al., (2013) observaron que el metanol en condiciones cercanas a un $\mathrm{pH} 3-3.5$, favorecía la hidrólisis de los enlaces glucosídicos aumentando la actividad antioxidante de compuestos asociados a azúcares; destacando que la aplicación de solventes acidificados implica la destrucción de las membranas celulares de la muestra, desencadenando una desestabilización en estos compuestos, y por tanto provocando la liberación de la mayor parte de los polifenoles hidrolizables que se encuentran atrapados o unidos a la matriz vegetal.

\section{Actividad antifúngica}

Desde el punto de vista microbiológico, diversos estudios reportan actividad antibacteriana, antiviral y antifúngica por parte de los polifenoles; así como también se ha descrito su efecto inhibitorio sobre exotoxinas (Perez et al., 2008). En el presente estudio, la actividad biológica fue evaluada sobre los microorganismos Cryptococcus laurentii (levadura) y Cladophialophora (moho). En esta investigación y en concomitancia con el estudio realizado por Amiri et al., (2008) se consideró el efecto fungistático cuando se observó una reactivación del crecimiento del micelio luego de siete días de incubación, y efecto fungicida cuando no se produjo crecimiento miceliar del patógeno luego del periodo de incubación y observación que correspondió al periodo de 20 días. De acuerdo a esto, el efecto fungicida en el laboratorio se refiere al agente que disminuye en un $99,9 \%$ las colonias a partir de un inoculo de subcultivo puro (Amiri et al., 2008).

Los resultados obtenidos por el método de difusión radial en agar a través de la presencia de halos de inhibición, se resumen en la tabla 3. El extracto de Nalca a una concentración de $2400 \mathrm{ug} / \mathrm{ml}$ (extracto puro) ejerció en condiciones de laboratorio un efecto fungistático y fungicida sobre ambos microorganismos; puesto que en el día 7 se cuantificaron halos de inhibición de $17 \pm 0.6 \mathrm{~mm}$ (Cryptococcus laurentii) y de $23 \pm 0.9 \mathrm{~mm}$ (Cladophialophora); mientras que en el día 20 no se observó reactivación en el crecimiento de ambos hongos ( $16 \pm 0.7 \mathrm{~mm}$ y $22 \pm 0.3 \mathrm{~mm}$ para Cryptococcus laurentii y Cladophialophora respectivamente) (Figura 1 y 2 ). De acuerdo a esto y a la incapacidad de los microorganismos estudiados de crecer al estar en contacto con el extracto de Nalca; es posible atribuirle un efecto fungicida ya que se asume una inactivación del crecimiento miceliar y de la germinación conidial (Amiri et al., 2008; Imtiaj et al., 2005). Esto es coherente con lo expuesto por Perez et al., (2008); quién sugirió una alta susceptibilidad de patógenos alimentarios (Staphylococcus aureus, Streptococcus mutans, Pseudomonas aeruginosa, Salmonella enteritidis, Bacillus cereus y Escherichia coli O157:H7) frente a extractos ricos en compuestos polifenólicos.

Tabla 3: Actividad biológica. Efecto inhibitorio de Nalca sobre el crecimiento de Cryptococcus laurentii y Cladophialophora de acuerdo al periodo de incubación.

\begin{tabular}{|c|c|c|c|c|c|c|c|}
\hline \multirow{2}{*}{ Microorganismo } & \multirow{2}{*}{$\begin{array}{c}\text { Concentración } \\
(\mathrm{ug} / \mathrm{ml})\end{array}$} & \multicolumn{6}{|c|}{ Halo de inhibición (mm) } \\
\hline & & Día 3 & Día 5 & Día 7 & Día 9 & Día 14 & Día 20 \\
\hline \multirow{6}{*}{$\begin{array}{c}\text { Cryptococcus } \\
\text { laurentii }\end{array}$} & $0.00^{*}$ & - & - & - & - & - & - \\
\hline & 0.24 & - & - & - & - & - & - \\
\hline & 2.40 & - & - & - & - & - & - \\
\hline & 24.0 & - & - & - & - & - & - \\
\hline & 240.0 & $9.0 \pm 2.1$ & - & - & - & - & - \\
\hline & 2400.0 & $26.0 \pm 0.3$ & $21 \pm 0.5$ & $17 \pm 0.6$ & $16 \pm 0.8$ & $16 \pm 0.5$ & $16 \pm 0.7$ \\
\hline \multirow{6}{*}{ Cladophialophora } & $0.00^{*}$ & - & - & - & - & - & - \\
\hline & 0.24 & - & - & - & - & - & - \\
\hline & 2.40 & - & - & - & - & - & - \\
\hline & 24.0 & $8.0 \pm 1.8$ & - & - & - & - & - \\
\hline & 240.0 & $14 \pm 1.3$ & $7.3 \pm 0.8$ & - & - & - & - \\
\hline & 2400.0 & $39 \pm 0.4$ & $28 \pm 1.7$ & $23 \pm 0.9$ & $22 \pm 0.4$ & $22 \pm 0.6$ & $22 \pm 0.3$ \\
\hline
\end{tabular}

En términos comparativos, cabe mencionar que drogas comerciales como fluconazol y flucitosina (a concentraciones que van desde los $0.12-64 \mathrm{ug} / \mathrm{ml}$ ), han exhibido in vitro un efecto antifúngico sobre diversas especies del género Cladophialophora (Vitale et al., 2009). Por otra parte, anfotericina b en un rango de 0.125 $-2 \mathrm{ug} / \mathrm{ml}$ inhibió en condiciones de laboratorio el crecimiento de Cryptococcus laurentii (Pedroso et al., 2006). 

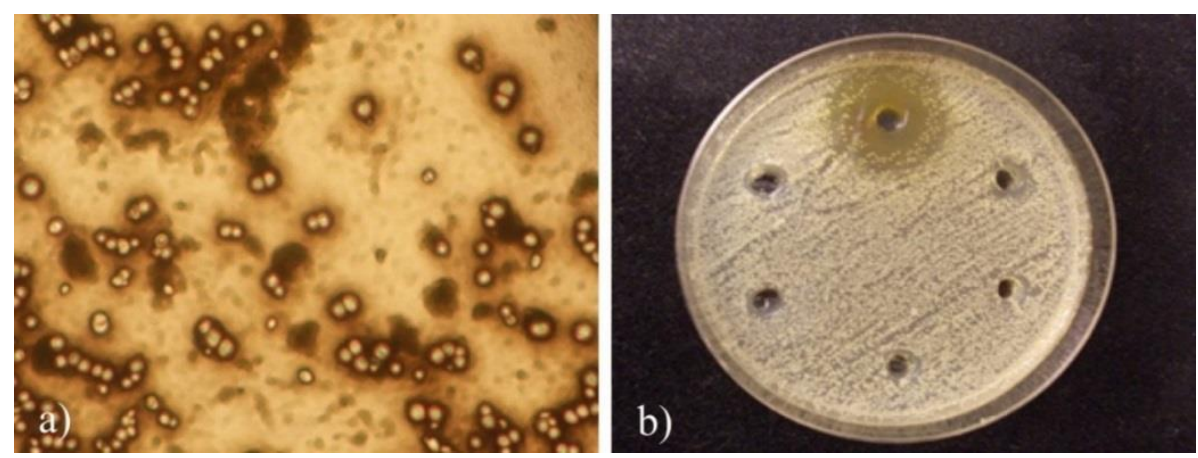

Fig. 1: Cryptococcus laurentii. a) Observación microscópica (examen en fresco, tinta china), y b) Efecto ejercido por el extracto de peciolo.
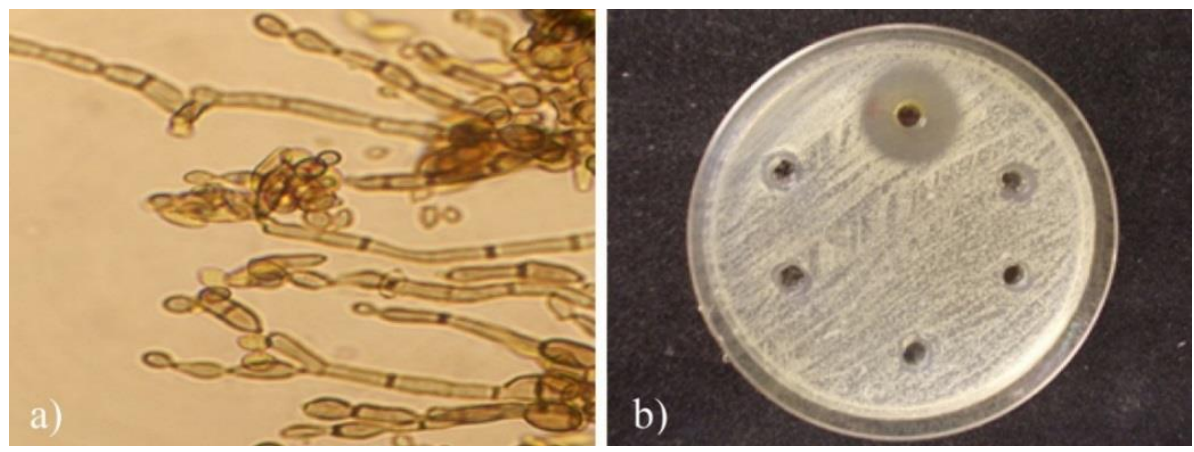

Fig. 2: Cladophialophora. a) Observación microscópica (examen en fresco, tinta china), y b) Efecto ejercido por el extracto de peciolo.

Es posible atribuir el efecto fungistático y/o fungicida al alto contenido de polifenoles totales y capacidad antioxidante reportado en el peciolo de nalca. De acuerdo a Tajkarimi et al., (2010), la compleja mezcla de compuestos (usualmente de bajo peso molecular) que forman parte de las especies vegetales (ácidos fenólicos, flavonoides, glucósidos, ácidos orgánicos, compuestos volátiles, entre otros), y su actuar sinérgico es lo que contribuye a su actividad. De hecho, la capacidad antimicrobiana de los compuestos polifenólicos, como flavonoides sobre bacterias y hongos está mediada por su acción en las membranas celulares microbianas; puesto que interactúan con las proteínas de membrana presentes en la pared celular, lo que conduce a una mayor permeabilidad y disrupción de la membrana (Upadhyay et al., 2014). Según Avello et al., (2012), uno de los posibles mecanismos antifúngicos está relacionado a la volatilidad y bajo peso molecular de la mayoría de los compuestos mencionados, pudiendo atravesar estructuras de resistencia celular de las especies fúngicas.

De esta manera, el daño de la membrana citoplasmática, la interferencia en el metabolismo del folato, y la reducción en el contenido de ergosterol favorecen la formación de poros por los cuales difunden iones y moléculas (fundamentalmente $\mathrm{K}+\mathrm{y} \mathrm{H}+$ ), que finalmente comprometen la viabilidad de la membrana y que según las concentraciones del extracto aplicadas afectaría la producción de ATP (Avello et al., 2012). Yahyzadeh et al., (2008), sugieren que la mezcla de los miles compuestos presentes en los extractos, evitarían el desarrollo de resistencia por parte de los microorganismos patógenos, ya que, cada uno de los componentes tienen su propia actividad y mecanismo biológico, por lo que es difícil correlacionar la acción de un compuesto único, debido a que el potencial antimicrobiano es el resultado del actuar sinérgico de los constituyentes. Los resultados fungicidas obtenidos en el presente estudio son prometedores, puesto que Pereira-Dias et al., (2000) han reportado en quesos refrigerados la presencia de Cryptococcus laurentii; levadura que interfiere en la maduración de este producto metabolizando el ácido láctico (elevando el pH) y favoreciendo el crecimiento de bacterias proteolíticas. Microorganismos que finalmente generan fructificaciones, sabores levaduriformes indeseables y una textura desagradable para la apariencia del producto. Por otra parte, Cladophialophora ha sido aislado en harina de maíz no integral, tomates, zanahorias, manzanas, frutillas y peras (Romao-Dumaresq et al., 2016).

\section{CONCLUSIONES}

En el presente estudio se reportó la composición química proximal, capacidad antioxidante y actividad biológica de peciolo de nalca, destacando su potencial al ser comparado con otras especies vegetales de consumo masivo. Los resultados obtenidos sugieren que Nalca es una rica fuente natural de antioxidantes, los cuales participan directamente en su alta capacidad biológica y antioxidante. Esta información permite 1) 
revalorizar la nalca como un producto alimenticio, confiriéndole un valor agregado que le permita ser insertada en un sistema de comercialización formal; y 2) como objeto de investigación a partir de su acción antagonista sobre Cryptococcus laurentii y Cladophialophora; pudiendo ser considerada como una alternativa antimicrobiana en desarrollo.

\section{AGRADECIMIENTOS}

Los autores agradecen a las entidades a cargo de la Plataforma de movilidad académica y estudiantil de la alianza del pacífico en Colombia (VIII convocatoria) -ICETEX, APC (Agencia Presidencial de Cooperación Internacional de Colombia) y Cancillería colombiana-. A los laboratorios de análisis instrumental (ICYTAL) y microbiología clínica pertenecientes a la Universidad Austral de Chile; y al laboratorio de Ciencia de los alimentos de la Universidad Nacional de Colombia (Sede Medellín).

\section{REFERENCIAS}

Amiri, A.; R. Dugas; A.L. Pichot y G. Bompeix, In vitro and in vivo activity of eugenol oil (Eugenia caryophylata) against four important postharvest apple pathogens, Int. J. Food Microbiol.: 15, 126(1-2), 13-9 (2008)

AOAC, Association of Official Analytical Chemists, Official Methods of Analysis of AOAC International, 16th Ed., AOAC International, Gaithersburg, MD, USA (1996)

Asuntos Públicos, Instituto de Políticas Públicas, Informe País, Estado Del Medio Ambiente en Chile: Comparación, 19992015 (2016)

Avello Lorca, M.; C. López Canales; C. Gatica Valenzuela; E. Bustos Concha; A. Brieva Chait; E. Pastene Navarrete y M. Bittner Berner, Efectos antimicrobianos de extractos de plantas chilenas de las familias Lauraceae y Atherospermataceae, Rev. Cubana Plant. Med.: 17(1), 73-83 (2012)

Bauer, A.W.; W.M. Kirby; J.C. Sheriss y M. Turck, Antibiotic susceptibility testing by standardized single disk method, Am. J. Clin. Pathol.: 45, 493-496 (1996)

Brand-Williams, W.; M.E. Cuvelier y C. Berset, Use of a free radical method to evaluate antioxidant activity, Food Sci. Technol.: 28(1), 25-30 (1995)

Bujor, O.C.; C. Le Bourvellec; I. Volf; V.I. Popa y C. Dufour, Seasonal variations of the phenolic constituents in bilberry (Vaccinium myrtillus L.) leaves, stems and fruits, and their antioxidant activity, Food Chem.: 213, 58-68 (2016)

Cadaval, A.; B. Escauriaza; U. Barrutia; C. Pérez y J. Aranceta, Alimentos funcionales para una alimentación más saludable, pp. 9-52, Book. Senc., México (2005)

Cantón, E.; E. Martín y A. Espinel-Ingroff, Métodos estandarizados por el CLSI para el studio de la sensibilidad a los antifúngicos (documentos M27-A3, M38-A y M44.A), en: J Pemán, E Martín-Mazuelos, MC Rubio Calvo, editores, Guía Práctica de Identificación y Diagnóstico en Micología Clínica. $2^{\mathrm{a}}$ Ed., Revista Iberoamericana de Micología, Bilbao, España (2007)

Dorta, E.; G. Lobo y M. González, Optimization of Factors Affecting Extraction of Antioxidants from Mango Seed. Food Bioproc. Tech.: 6(4), 1067-1081 (2013)

Gaviria Montoya, C.; C. Ochoa; N. Sánchez; C. Medina; M. Lobo; P. Galeano; A. Mosquera; A. Tamayo; Y. Lopera y B. Rojano, Actividad antioxidante e inhibición de la peroxidación lipídica de extractos de frutos de mortiño (Vaccinium meridionale Sw), BLACPMA: 8, 519-528 (2009)

Genskowsky, E.; L.A. Puente; J.A. Perez-Álvarez; J. Fernández-López; L.A. Muñoz y M. Viuda-Martos, Determination of polyphenolic profile, antioxidant activity and Antibacterial properties of Maqui [Aristotelia chilensis (Molina) Stuntz] a Chilean blackberry, J. Sci. Food Agric.: 96 (12), 4235-4242 (2016)

Georgé, S.; F. Tourniaire; H. Gautier; P. Goupy; E. Rock y C. Caris-Veyrat, Changes in the contents of carotenoids, phenolic compounds and vitamin $\mathrm{C}$ during technical processing and lyophilisation of red and yellow tomatoes, Food Chem.: 124(4), 1603-1611 (2011)

Ibrahim, M.R.; H.M. El-Banna; I.I. Omara y M.A. Suliman, Evaluation of nutritive value of some citrus pulp as feedstuffs in rabbits diets. Pakistan J. Nutr.: 10(7), 667-674 (2011)

Iglesias, I.; J. Graell; G. Echeverría y M. Vendrell, Differences in fruit color development, anthocyanin content, yield and quality of seven "Delicious" apple strains, Fruit Varieties J.: 53(1), 133-145 (1999)

Imtiaj, A.; S.A. Rahman; S. Alam; R. Parvin; K.M. Farhana; S.B. Kim y T.S. Lee, Effect of Fungicides and Plant Extracts on the Conidial Germination of Colletotrichum gloeosporioides Causing Mango Anthracnose, Mycobiology: 33(4), 200-205 (2005)

Jeszka-Skowron, M.; A. Zgoła-Grześkowiak; E. Stanisz y A. Waśkiewicz, Potential health benefits and quality of dried fruits: Goji fruits, cranberries and raisins, Food Chem.: 221, 228-236 (2017)

Ju, Z.Y. y L.R. Howard, Effects of solvent and temperature on pressurized liquid extraction of anthocyanins and total phenolic from dried red grape skin, J. Agric. Food Chem.: 51(18), 5207-5213 (2003)

Lu, J.M.; P.H. Lin; Q. Yao y C. Chen, Chemical and molecular mechanisms of antioxidants: Experimental approaches and model systems, J. Cell. Mol. Med.: 14(4), 840-860 (2010) 
Mazo, J.E.; D. Cantillo; K. Rodríguez y J.A. Yepes, Aumento de polifenoles en el sustrato de algarrobillo (Samanea saman (Jacq.) Merr.) mediante fermentación en estado sólido con Rhizopus sp (CMPUJ H041), Inf. Tecnol.: 27(6), 77-84 (2016) MINSAL, Ministerio de Salud, Norma Técnica para la supervisión de niños y niñas de 0 a 9 en la Atención Primaria, Programa Nacional de Salud de la Infancia, Santiago, Chile: MINSAL Gobierno de Chile (2014)

Morillas-Ruiz, J.M. y J.M. Delgado-Alarcón, Nutritional analysis of vegetable food with different origins: Evaluation of antioxidant capacity and phenolic total compounds, Nutr. Clin. Diet. Hosp.: 32(2), 8-20 (2012)

Oyvind, A. y M. Kenneth, Separation and Quantification of Flavonoids, In Flavonoids: chemistry, biochemistry and applications by A. Oyvind y M. Kenneth, pp 1-31 (Ed.) Taylor \& Francis Group, New York (2006)

Pedroso, R.S.; J.C. Ferreira y R.C. Candido, In vitro susceptibility to antifungal agents of environmental Cryptococcus spp isolated in the city of Ribeirão Preto, São Paulo, Brazil, Mem. Inst. Oswado Cruz: 101(3), 239-243 (2006)

Pereira-Dias, S.; M.E. Potes; A. Marinho; M. Malfeito-Ferreira y V. Loureiro, Characterisation of yeast flora isolated from an artisanal Portuguese ewes' cheese, Int. J. Food Microbiol.: 60(1), 55-63 (2000)

Pérez Gutiérrez, R.M.; S, Mitchell y R.V. Solis, Psidium guajava: A review of its traditional uses, phytochemistry and pharmacology, J. Ethnopharmacol.: 117(1), 1-27 (2008)

Petzold, G.; G. Catril y C. Duarte, Caracterización fisicoquímica de peciolos de pangue (Gunnera tinctoria), Rev. Chilena Nutr.: 33(3), 539-543 (2006)

Prior, R.L.; H. Hoang; L. Gu; X. Wu; M. Bacchiocca; L. Howard; M. Hampsch-Woodill; D. Huang; B. Ou y R. Jacob, Assays for hydrophilic and lipophilic antioxidant capacity (oxygen radical Absorbance capacity (ORACFL) of plasma and other biological and food samples, J. Agric. Food Chem.: 51(11), 3273-3279 (2003)

Ramirez, J.E.; R. Zambrano; B. Sepúlveda; E.J. Kennelly y M.J. Simirgiotis, Anthocyanins and antioxidant capacities of six Chilean berries by HPLC-HR-ESI-ToF-MS. Food Chem.: 176, 106-114 (2015)

Ratti, C., Hot air and freeze-drying of high-value foods: a review, J. Food Eng.: 49, 311-319 (2001)

Romão-Dumaresq, A.S.; M.N. Dourado; L.C. Fávaro; R. Mendes; A. Ferreira y W.L. Araújo, Diversity of cultivated Fungi Associated with Conventional and Transgenic Sugarcane and the Interaction between Endophytic Trichoderma virens and the Host Plant, PLoS One: 11(7), e0158974 (2016)

Rostagno, M.A.; M. Palma y C.G. Barroso, Ultrasound-assisted extraction of soy isoflavones, J. Chromatogr. A: 1012, 119$128(2003)$

Ruiz, A.; I. Hermosín-Gutierrez; C. Mardones; C. Vergara; E. Herlitz; M. Vega; C. Dorau; P. Winterhalter y D. von Baer, Polyphenols and antioxidant activity of Calafate (Berberis microphylla) fruits and other native berries from Southern Chile, J. Agric. Food Chem.: 58, 6081-6089 (2010)

Singleton, V.L. y J.A. Rossi, Colorimetry of total phenolics with phosphomolybdic-phosphotungstic acid reagents, Am. J. Enol. Vitic.: 16:144-158 (1965)

Slavin, J., Impact of the proposed Definition of Dietary Fiber on Nutrient Databases. J. Food Compos. Anal.: 16(3), 287291 (2003)

Sulaiman, S.F.; A.A.B. Sajak; K.L. Ooi; Supriatno y E.M. Seow, Effect of solvents in extracting polyphenols and antioxidants of selected raw vegetables, J. Food Comp. Anal.: 24(4-5), 506-515 (2011)

Tajkarimi, M.M.; S.A. Ibrahim y D.O. Cliver, Antimicrobial herb and spice compounds in food, Food Control: 21(9), 11991218 (2010)

Tatsuzawa, F.; N. Saio; A. Shigihara; T. Honda; K. Toki; K. Shinoda; T. Yukawa y K. Miyoshi, An acylated cyaniding 3,7diglucoside in the bluish flowers of Bletilla striata Murasaki Shikibu (Orchidaceae), J. Japan. Soc. Hort. Sci.: 79(2), 215$220(2010)$

Upadhyaya, N.M.; R. Mago; B.J. Staskawicz; M.A. Ayliffe; J.G. Ellis y P.N. Dodds, A bacterial type III secretion assay for delivery of fungal effector proteins into wheat. Mol. Plant Microbe Interact.: 27(3), 255-264 (2014)

Vega, A.; J.A. De León; M.S. Reyes, Determinación del contenido de Polifenoles Totales, Flavonoides y Actividad Antioxidante de 34 Cafés Comerciales de Panamá, Inf. Tecnol.: 28(4), 29-38 (2017)

Vitale R.G.; M. Perez-Blanco y G.S. de Hoog, In vitro activity of antifungal drugs against Cladophialophora species associated with human chromoblastomycosis. Med Mycol.: 47, 35-40 (2009)

Wilson, A.L.; E. Buckley; J.D. Buckley y S. Bogomolova, Nudging healthier food and beverage choices through salience and priming. Evidence from a systematic review, Food Qual. Prefer.: 51, 47-64 (2016)

Yahyzadeh, M.; R. Omidbaigi; R. Zare y H. Taheri, Effect of some essential oils onmycelial growth of Penicillium digitatum Sacc, World J. Microbiol. Biotechnol.: 24: 1445-2150 (2008)

Zamorano, P.; B. Rojano; M. Morales; H. Magariños; P. Godoy y O. Muñoz, Biological and antioxidant activity of Gunnera tinctoria (Nalca), J. Med. Plants Res., 11(17), 318-330 (2017) 
